\title{
Patients seeking more involvement at medical meetings
}

\author{
Cite as: CMAJ 2018 May 14;190:E602. doi: 10.1503/cmaj.109-5597
}

Posted on cmajnews.com on Apr. 24, 2018.

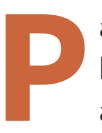

atient involvement at clinical and health policy conferences in Canada is fast becoming more than just a nod to patient engagement. Patient groups want substantive involvement in planning meetings, being on the program, and receiving financial support for the roles they are playing.

Witness the increasing importance of the "Patients Included" designation granted to medical conferences that meet several conditions for patient participation, including paying for the travel and accommodation of patient participants. Started in 2010, the movement aims to provide a means for organizations to demonstrate their commitment "to incorporating the experience and insights of patients." Some conferences, such as the annual meetings of the Canadian Agency for Drugs and Technologies in Health (CADTH) and Health Quality Ontario, have achieved this designation for a few years.

Although many believe the involvement of patients in health care conferences is productive and instructional, it can also be disorienting for policy-makers and medical experts unused to having patients or patient advocates involved in their deliberations. At CADTH's recent annual meeting, for example, patients on social media served as kind of a Greek chorus, providing ongoing commentary on the meeting.

"Including [patients as partners] is seen as disturbing to the panellists, suggesting [patient inclusion] has a long way to go to build bridges between stakeholders," the Patient Critical Co-op group tweeted from the meeting. "When you are talking about 'key opinion leaders in the

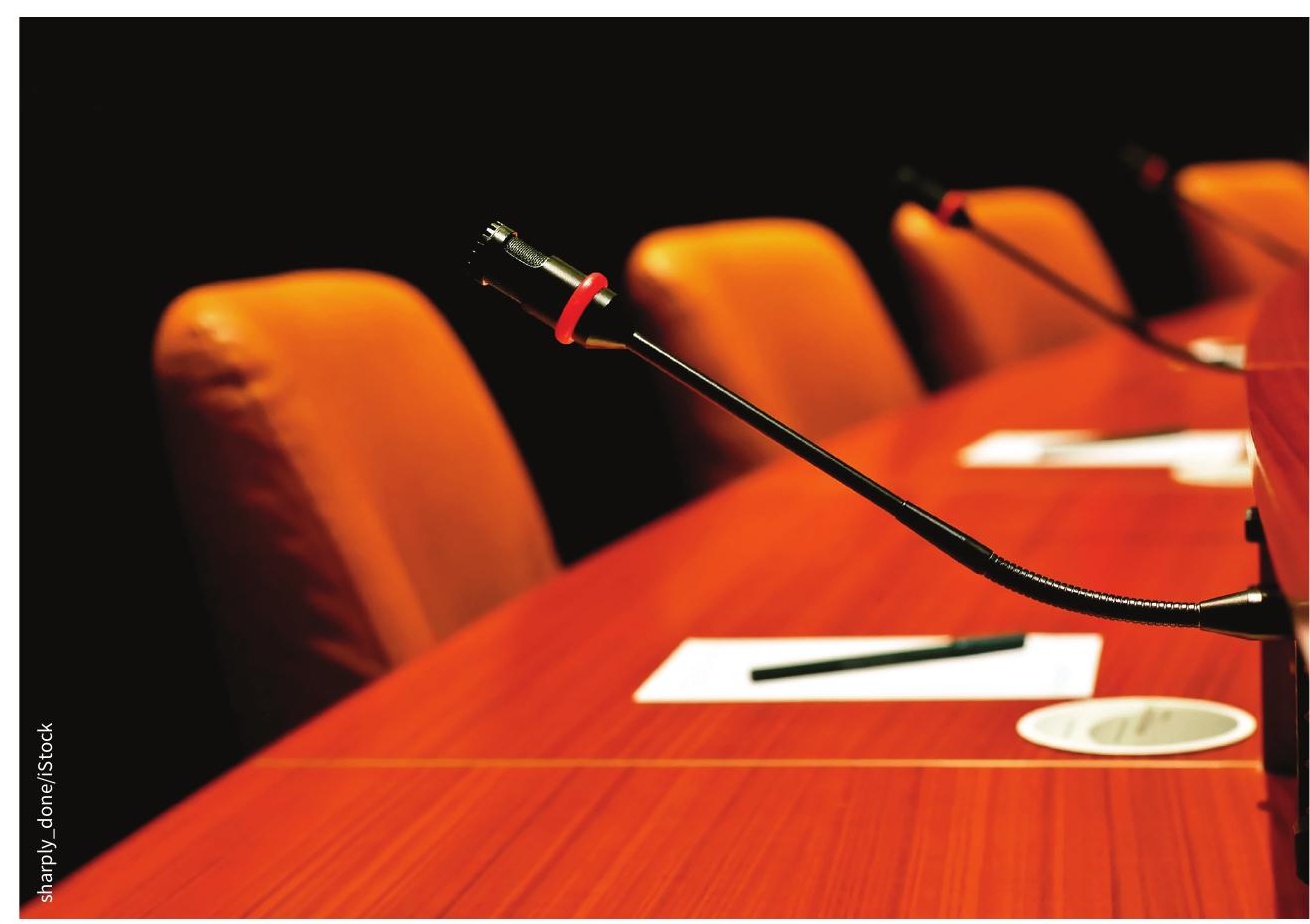

Patient groups want patients to have more time at the microphones at medical conferences.

country' who can champion change why are patients not empowered in the same way?" was another comment that was retweeted many times.

CADTH provided financial support for 30 patient representatives to attend the meeting, where there were sessions focused on the patient experience and patient engagement. There was also patient representation on the panels at several sessions.

"From my experience ... when patients are in the room with clinicians and others, the nature of the conversation changes," said John Abbott, deputy minister of health for Newfoundland and Labrador. "Many of us in our jurisdictions pay lip service to it, but we really need to do a lot more around bringing the patient voice and experience at all levels."

The CADTH meeting also demonstrated that patient representatives do not always speak with one voice. There were acrimonious exchanges between those who supported pharmaceutical funding for patient organizations and those who opposed it, leading one speaker to withdraw from the program.

"We can't lump all patients together and say they are all the same," said CADTH President and CEO Brian O'Rourke.

Pat Rich, Ottawa, Ont. 